\title{
Effect of Ba Substitution on the Structural and Magnetic Properties of $\mathrm{BiFeO}_{3}$
}

\author{
V. Srinivas ${ }^{1}$, A. T. Raghavender ${ }^{2}$, K. Vijaya Kumar ${ }^{3 *}$ \\ ${ }^{1}$ Department of Physics, Government Institute of Electronics, Secunderabad, TS, India \\ ${ }^{2}$ Department of Electronics and Communication Engineering, Nishitha College of Engineering and Technology, \\ Hyderabad, TS, India \\ ${ }^{3}$ Department of Physics, JNTUH College of Engineering Jagtial, Nachupally (Kondagattu), Karimnagar-Dist., TS, India \\ Email: "kvkphd@gmail.com
}

Received 28 December 2015; accepted 29 February 2016; published 4 March 2016

Copyright ( 2016 by authors and Scientific Research Publishing Inc.

This work is licensed under the Creative Commons Attribution International License (CC BY). http://creativecommons.org/licenses/by/4.0/

(c) (i) Open Access

\begin{abstract}
$\mathrm{Bi}_{1-\mathrm{x}} \mathrm{Ba}_{\mathrm{x}} \mathrm{FeO}_{3}(0 \leq \mathrm{x} \leq 0.3)$ nanopowders were synthesized using sol-gel technique. The structural and magnetic properties were investigated using X-ray diffraction, SEM and VSM. As $\mathrm{Ba}^{2+}$ doping concentration was increased, the structure of the samples changed from rhombohedral to tetragonal or monoclinic. The structural change might be an important factor for achieving the ferroelectric properties in this material. The lattice parameters were observed to increase with increase in $\mathrm{Ba}^{2+}$ concentration. All the $\mathrm{M}-\mathrm{H}$ loops showed the ferromagnetic behavior. Magnetization was observed to enhance with increase in Ba concentration. The enhancement in the magnetization due to $\mathrm{Ba}^{2+}$ doping may be due to the replacement of $\mathrm{Bi}^{3+}$ ions by $\mathrm{Ba}^{2+}$ which might have resulted in the suppression of spiral spin structure.
\end{abstract}

\section{Keywords}

Multiferroic Material, Structural, Magnetic Properties

\section{Introduction}

$\mathrm{BiFeO}_{3}$ (BFO) multiferroic materials in nano, bulk and in thin film form have been extensively investigated since the last decade. These materials were successfully used in many technological applications; therefore still lot of research work is going on. BFO is an interesting material due to the co-existence of G-type antiferroicmagnetic (AFM) structure having Néel temperature around $640 \mathrm{~K}$ and ferroelectric polarization with Curie tem-

*Corresponding author.

How to cite this paper: Srinivas, V., Raghavender, A.T. and Vijaya Kumar, K. (2016) Effect of Ba Substitution on the Structural and Magnetic Properties of $\mathrm{BiFeO}_{3}$. World Journal of Nano Science and Engineering, 6, 38-44.

http://dx.doi.org/10.4236/wjnse.2016.61004 
perature around $1000 \mathrm{~K} \mathrm{[1]} \mathrm{[2].} \mathrm{BFO} \mathrm{is} \mathrm{considered} \mathrm{to} \mathrm{be} \mathrm{superior} \mathrm{candidate} \mathrm{for} \mathrm{the} \mathrm{next} \mathrm{generation} \mathrm{devices} \mathrm{such}$ as spintronics, piezoelectric sensors, optoelectroinic devices, non-volatile memories, high density micro actuators etc. [3] [4]. The spontaneous magnetization in BFO could be induced by changing the Fe-O-Fe bond angle or by statistical octahedral distribution of Fe [5] [6]. In BFO, it is believed that, Bi 6s lone pair of electrons is responsible for ferroelectricity while, the partially filled Fe $d$ orbitals lead to magnetic ordering. Room temperature ferromagnetic properties of rare earth, transition metal ions doped BFO materials were observed by several researchers. The enhanced magnetization was observed in BFO due to the divalent, trivalent and rare earth ions on the Fe-site [7] [8]. BFO has rhombohedrally distorted perovskite structure $\left(\mathrm{ABO}_{3}\right)$ belonging to $\mathrm{R} 3 \mathrm{c}$ space group and a complicated spin structure [1]. BFO possess weak ferromagnetic order and ferroelectric polarization. Due to high volatile nature of $\mathrm{Bi}$, oxygen vacancies are produced and due to multiple oxidant states of $\mathrm{Fe}$ ions, it causes a high leakage current which degrades ferroelectric properties [9] [10]. The ferromagnetism in BFO is produced due to spin canting which vanishes due to the spiral spin structure of the magnetic domains [9]-[11]. Due to these limitations, pure BFO has very few applications. In order to improve the magnetic and electrical properties of BFO, elements such as $\mathrm{Ba}^{2+}, \mathrm{Sr}^{2+}, \mathrm{Ca}^{2+}, \mathrm{La}^{3+}, \mathrm{Gd}^{3+}, \mathrm{Ti}^{4+}, \mathrm{Mn}^{4+}, \mathrm{Nb}^{5+}$ etc., have been substituted in tetrahedral (A) and octahedral (B) sites of pure BFO by which the multiferroic properties were observed to improve.

$\mathrm{Ba}^{2+}$ doping in A site was observed to improve multiferroic properties of BFO. Substituting $\mathrm{Ba}^{2+}$ in BFO distorts its original structure due to larger ionic radii of $\mathrm{Ba}$ and changes its cycloidal spin structure to a canted spin structure resulting in the magnetization at room temperature. Also, addition of $\mathrm{Ba}^{2+}$ in $\mathrm{BFO}$ is believed to reduce the oxygen vacancy related defects significantly which in turn improves the electrical properties [12]. The synthesis of single phase BFO remains to be challenging task. Several researchers have attempted to prepare BFO using different synthesis techniques and yet the secondary phases are difficult to avoid, but the defects related to the oxygen vacancies have been reduced [13]. In this present work, we intend to investigate and present the results of the structural and magnetic changes taking place with $\mathrm{Ba}^{2+}$ doping in BFO.

\section{Experimental}

$\mathrm{Ba}^{2+}$ doped $\mathrm{BFO}$ was synthesized using sol-gel method [8] [14] [15]. The A.R Grade citric acid $\left(\mathrm{C}_{6} \mathrm{H}_{8} \mathrm{O}_{7} \cdot \mathrm{H}_{2} \mathrm{O}\right)$, bismuth nitrate $\left(\mathrm{Bi}\left(\mathrm{NO}_{3}\right)_{3} \cdot 5 \mathrm{H}_{2} \mathrm{O}\right)$, barium nitrate $\left(\mathrm{Ba}\left(\mathrm{NO}_{3}\right)_{3} \cdot 4 \mathrm{H}_{2} \mathrm{O}\right)$, ferric nitrate $\left(\mathrm{Fe}\left(\mathrm{NO}_{3}\right)_{3} \cdot 9 \mathrm{H}_{2} \mathrm{O}\right)(\geq 99 \%)$ were used as starting materials. The entire synthesis process is described elsewhere [8] [14] [15]. The molar ratio of metal nitrates to citric acid was taken as 1:3. The metal nitrates were dissolved together in a minimum amount of de-ionized water to get a clear solution. An aqueous solution of citric acid was mixed with metal nitrates solution, then ammonia solution was slowly added to adjust the $\mathrm{pH}$ at 7 . The mixed solution was moved on to a hot plate with continuous stirring at $90^{\circ} \mathrm{C}$. During evaporation, the solution became viscous and finally formed a very viscous brown gel. When finally all remaining water was released from the mixture, the sticky mass began to bubble. After several minutes, the gel automatically ignited and burnt with glowing flints. The decomposition reaction would not stop before the whole citrate complex was consumed. The auto-ignition was completed within a minute, yielding the brown-colored ashes termed as a precursor. The as-prepared powders of all the samples were heat treated separately at $600^{\circ} \mathrm{C}$ for $8 \mathrm{~h}$ to get the final product.

The X-ray diffraction of the ferrite powders was carried out by using a Philips PW 1820 powder diffractometer with $\mathrm{CuK} \alpha$ graphite-monochromated radiation, operating at $40 \mathrm{kV}$ and $30 \mathrm{~mA}$, with solar slits and divergent and receiving slits of $0.2 \mathrm{~mm}$. The diffracted intensity was registered in the angular range $8^{\circ} \leq 2 \theta \leq 80^{\circ}$, with a step size of $0.02^{\circ}(2 \theta)$. The micrographs of all samples were taken on FEI Quanta FEG 200 High Resolution Scanning Electron Microscope. Room temperature magnetic properties were investigated using Lakeshore (USA) VSM 7410.

\section{Results and Discussions}

Figure 1 shows the $\mathrm{X}$-ray diffraction (XRD) patterns of $\mathrm{Bi}_{1-\mathrm{x}} \mathrm{Ba}_{\mathrm{x}} \mathrm{FeO}_{3}(\mathrm{x}=0.0,0.1,0.2,0.3)$ measured at room temperature. The XRD peaks show the typical rhombohedral type perovskite structure [16]. Apart from the main $\mathrm{BiFeO}_{3}$ peaks, few minor peaks belonging to $\mathrm{Bi}_{2} \mathrm{Fe}_{4} \mathrm{O}_{9} / \mathrm{Bi}_{24} \mathrm{Fe}_{2} \mathrm{O}_{39} / \mathrm{Bi}_{2} \mathrm{O}_{3}$ are also visible. During the synthesis process excess amount of $\mathrm{Bi}$ was added in order to avoid non-stoichiometry, therefore the secondary phases seems to appear in the prepared samples. Berbenni et al. [17] showed that, if $\mathrm{BFO}$ is annealed at temperatures $\geq$ $750^{\circ} \mathrm{C}$ the secondary phases such as $\mathrm{BiO}_{3}, \mathrm{Fe}_{2} \mathrm{O}_{3}, \mathrm{Bi}_{2} \mathrm{Fe}_{4} \mathrm{O}_{9}$ will disappears. It seems that higher annealing 


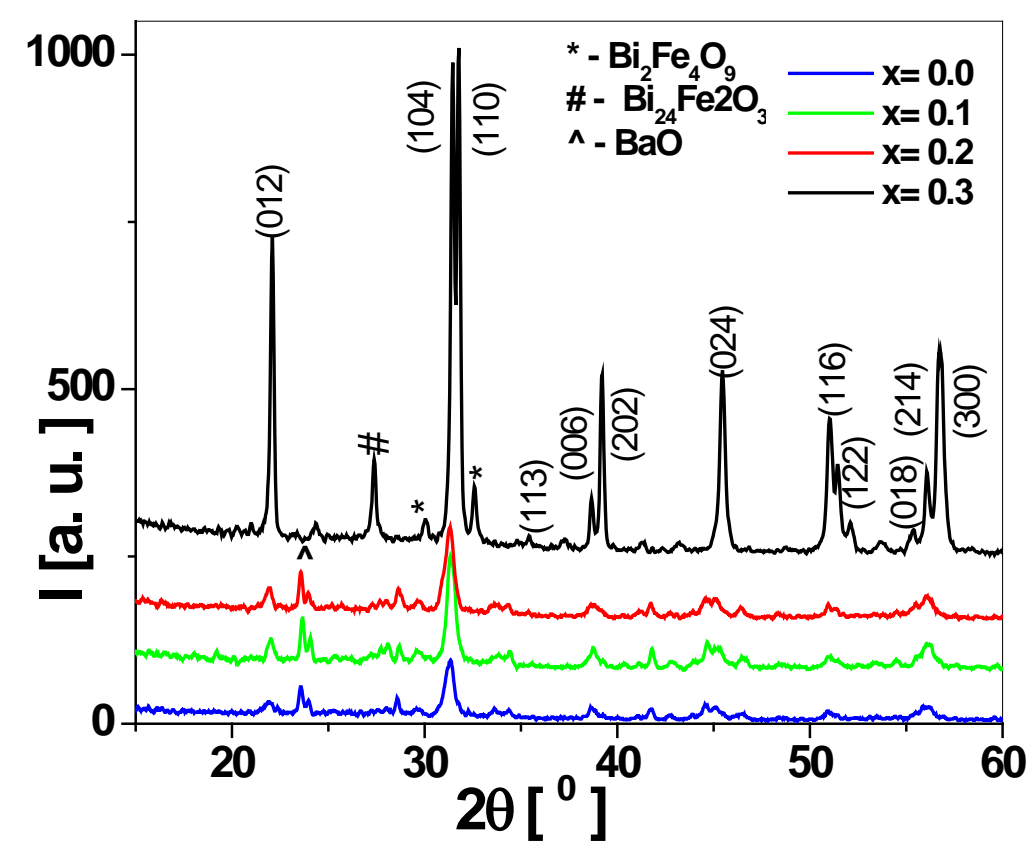

Figure 1. X-ray diffraction patterns of $\mathrm{Bi}_{1-\mathrm{x}} \mathrm{Ba}_{\mathrm{x}} \mathrm{FeO}_{3}(\mathrm{x}=0.0,0.1,0.2,0.3)$.

temperatures increase the intensity of characteristic BFO peaks and reduce the intensity of secondary phases but, may not be possible to avoid the secondary phases. Because, even though the samples were annealed at $800^{\circ} \mathrm{C}$ still the traces of the secondary phases are present [17].

The lattice parameters ( $a$ and $c$ ) were calculated using the XRD results based on the hexagonal distortion of the rhombohedral unit cell using the following relation and are listed in Table 1.

$$
\frac{1}{d^{2}}=\frac{4}{3} \frac{\left(h^{2}+k^{2}+h k\right)}{a^{2}}+\frac{l^{2}}{c^{2}}
$$

where $d$ is the inter-planar spacing and $(h k l)$ are the miller indices.

From the Table 1, it is observed that, the lattice parameters increase slightly with increasing Ba doping concentration which is very well in agreement with previously published work on the same materials [18]. With increasing $\mathrm{Ba}^{2+}$ doping content the peak positions shifts slightly towards left indicating the increment in lattice parameters. Since the ionic radii of $\mathrm{Ba}^{2+}(2.173 \AA)$ is larger than $\mathrm{Bi}^{3+}(1.55 \AA), \mathrm{Ba}^{2+}$ substitution leads to increase in the unit cell volume. The separation between (104) and (110) diffraction peaks are reduced with Ba substitution which may imply that rhombohedral structure might have distorted to either tetragonal or monoclinic structure [19]. These structural changes with $\mathrm{Ba}^{2+}$ doping in BFO might be an important factor considered for ferroelectric properties of these materials.

Figure 2 shows the SEM micrographs for $\mathrm{x}=0.0$ and 0.2 samples. SEM analysis shows that, the average grain size is around $200 \mathrm{~nm}$. There is no significant change in the grain size with the increase in $\mathrm{Ba}^{2+}$ doping concentration.

Figure 3 shows the hysteresis loops of $\mathrm{Bi}_{1-\mathrm{x}} \mathrm{Ba}_{\mathrm{x}} \mathrm{FeO}_{3}(\mathrm{x}=0.0,0.1,0.2,0.3)$ samples measured at room temperature with a maximum applied field of $15 \mathrm{kOe}$. All the samples clearly exhibit a nonlinear magnetization dependence on the magnetic field. The derived parameters from the hysteresis loops such as maximum magnetization $\left(M_{\text {Max }}\right)$, remnant magnetization $\left(M_{r}\right)$ and coercive field $\left(H_{c}\right)$ are listed in Table 1 . Except for $\mathrm{x}=0.0$, the areas of other loops resembles to square shape rather than the regular S-shape. The loop areas for $\mathrm{x}=0.1$ and 0.2 are almost similar. But for, higher $\mathrm{Ba}^{2+}$ doping $(\mathrm{x}=0.3)$, the area of the loop appears to be small. The magnetization was observed to enhance with the increase in $\mathrm{Ba}^{2+}$ concentration up to $\mathrm{x}=0.2$ and with the further increase in $\mathrm{x}=0.3$, the magnetization is lowered. In our samples, higher $\mathrm{Ba}^{2+}$ doping has resulted for the reduced magnetization. The enhancement of Magnetization with $\mathrm{Ba}^{2+}$ concentration was previously observed [18] [20] [21]. It is observed that, impurity phases in the samples such as $\mathrm{Bi}_{24} \mathrm{Fe}_{2} \mathrm{O}_{39}$ and $\mathrm{BaO}$ do not exhibit room tem- 


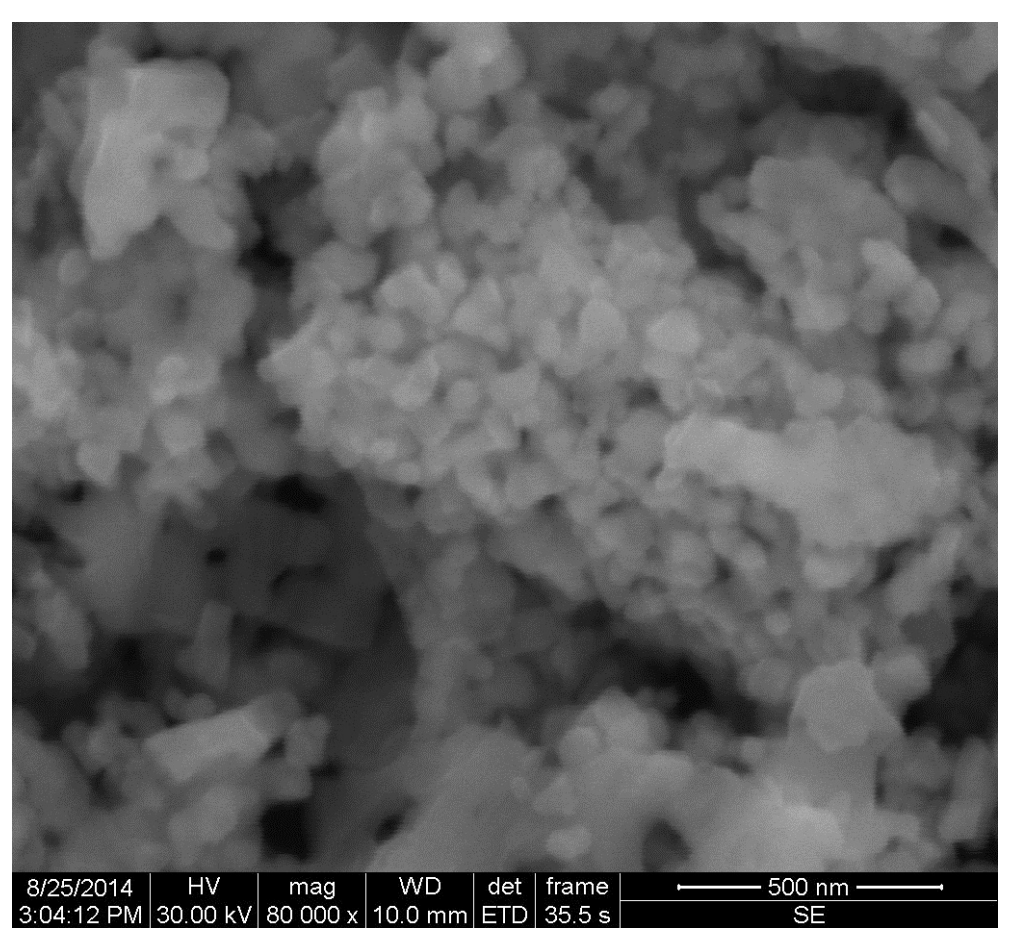

(a)

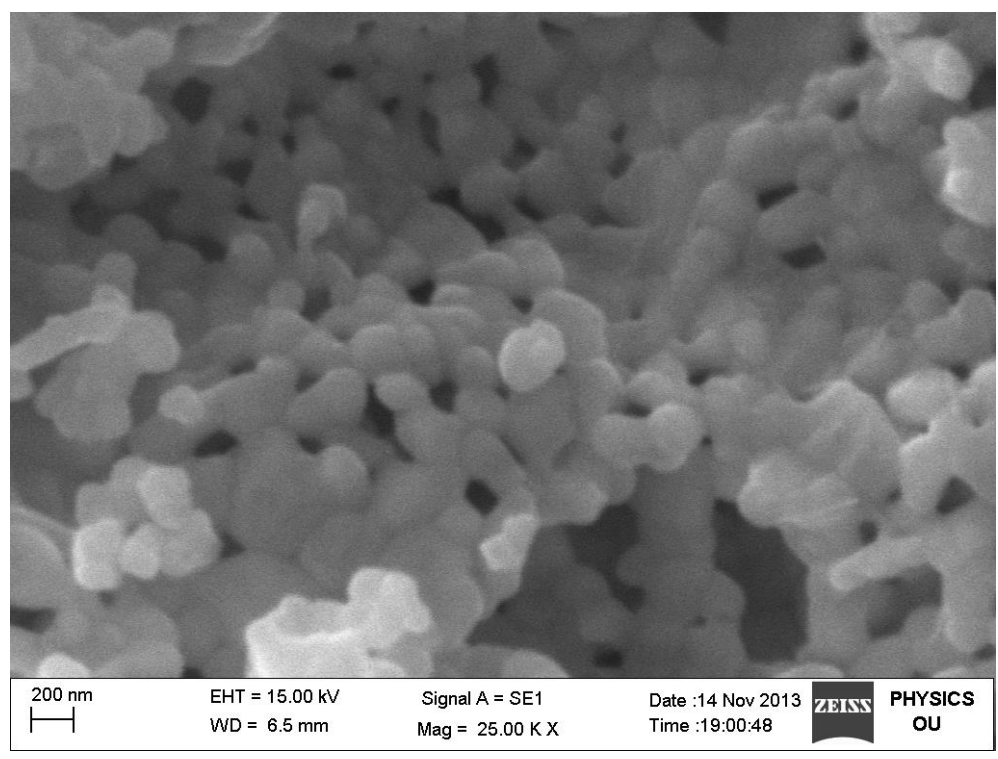

(b)

Figure 2. $\mathrm{SEM}$ micrographs of $\mathrm{Bi}_{1-\mathrm{x}} \mathrm{Ba}_{\mathrm{x}} \mathrm{FeO}_{3}$ (a) $\mathrm{x}=0.0$ and (b) $\mathrm{x}=0.2$.

Table 1. Lattice parameters, maximum magnetization, remnant magnetization and coercive filed of $\mathrm{Bi}_{1-\mathrm{x}} \mathrm{Ba}_{\mathrm{x}} \mathrm{FeO}_{3}$.

\begin{tabular}{cccccc}
\hline $\mathrm{x}$ & $\mathrm{a}(\AA)$ & $\mathrm{c}(\AA)$ & $M_{\text {Max }}(\mathrm{emu} / \mathrm{g})$ & $M_{r}(\mathrm{emu} / \mathrm{g})$ & $H_{c}(\mathrm{Oe})$ \\
\hline 0.0 & 5.69 & 13.55 & 2.05 & 0.27 & 0.12 \\
0.1 & 5.71 & 13.61 & 3.61 & 0.94 & 1.54 \\
0.2 & 5.70 & 13.57 & 4.89 & 1.35 & 1.15 \\
0.3 & 5.72 & 13.61 & 0.76 & 0.19 & 1.34 \\
\hline
\end{tabular}




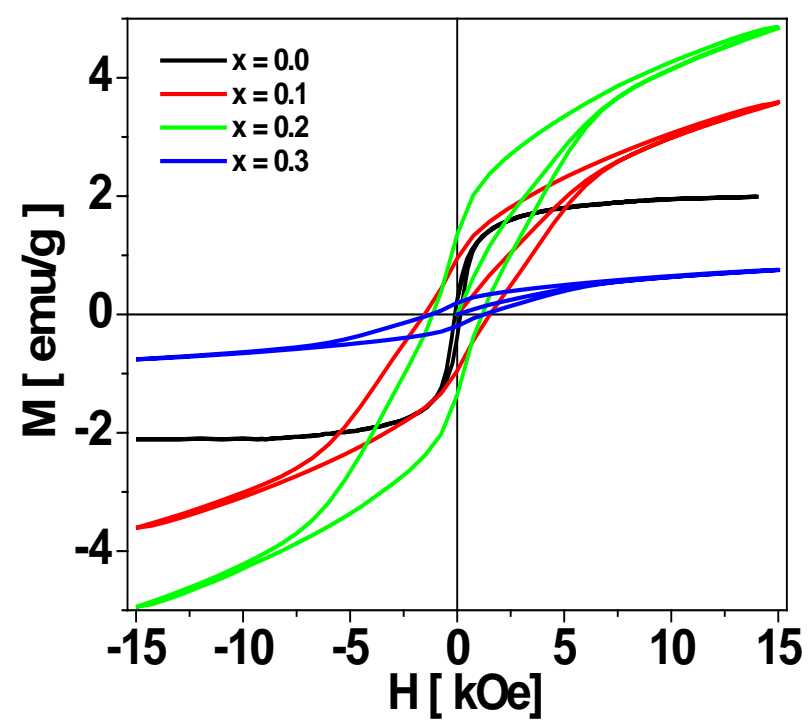

Figure 3. Magnetic hysteresis loops of $\mathrm{Bi}_{1-\mathrm{x}} \mathrm{Ba}_{\mathrm{x}} \mathrm{FeO}_{3}$ samples measured at room temperature.

perature magnetization, therefore the magnetic contribution from those secondary phases can be ruled out [22] [23].

It is observed that un-doped BFO exhibits ferromagnetic behavior in comparison to the antiferromagnetic nature of the bulk samples [21]. The ferromagnetic behavior of BFO may be due to the modulation of long-range spin cycloidal structure and also due to the antiferromagnetic nature of BFO [21]. In the antiferromagnetic nature of BFO the spin sublattice have ferromagnetic interactions within the sublattice and antiferromagnetic interactions within the sublattice [21]. With the increase of $\mathrm{Ba}^{2+}$ concentration, the grain size did not change significantly, therefore the effect of grain size in our magnetic analysis is not considered.

The enhanced magnetization in our case might be due to suppression of spin spiral structure of BFO and due to the replacement of $\mathrm{Bi}^{3+}$ ions by $\mathrm{Ba}^{2+}$ ions in the lattice site [24]. In which the system will destabilize by creating the charge imbalance. In this process, one oxygen vacancy will be created for every two alkaline metals to stabilize the system [21] [24]. This suppression of spiral spin structure by the oxygen vacancy enhances the ferromagnetism in $\mathrm{Ba}^{2+}$ substituted $\mathrm{BFO}$ [24].

\section{Conclusion}

$\mathrm{Ba}^{2+}$ doped BFO nanopowders were synthesized using sol-gel method. Lattice parameters were observed to increase with increasing $\mathrm{Ba}^{2+}$ doping concentration. The structure of the samples changed from rhombohedral to tetragonal or monoclinic with $\mathrm{Ba}^{2+}$ doping. The magnetization was observed to enhance with increasing $\mathrm{Ba}^{2+}$ concentration. The enhancement in the magnetization due to the $\mathrm{Ba}^{2+}$ doping may be due to the suppression of spiral spin structure because of the replacement of $\mathrm{Bi}^{3+}$ ions by $\mathrm{Ba}^{2+}$.

\section{Acknowledgements}

KVK is thankful to Dr. N. V. Ramana, Principal, JNTUH CEJ, Nachupally (Kondagattu), Karimnagar-Dist, for his support. Authors sincerely thank the Head and the technical persons of Sophisticated Analytical Instrumentation Facility (SAIF), Indian Institute of Technology (IIT) Madras, India, for providing the VSM and SEM measurements.

\section{References}

[1] Wang, J., Neaton, J.B., Zheng, H., Nagarajan, V., Ogale, S.B., Liu, B., Viehland, D., Vaithyanathan, V., Schlom, D.G.,

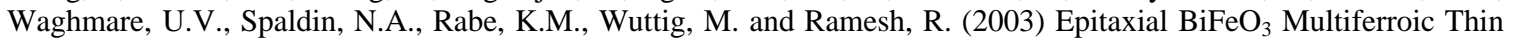
Film Heterostructures. Science, 299, 1719-1722. http://dx.doi.org/10.1126/science.1080615

[2] Feng, H.J., Wang, M., Liu, F., Duan, B., Tiam, J. and Guo, X. (2015) Enhanced Optical Properties and the Origin of 
Carrier Transport in $\mathrm{BiFeO}_{3} / \mathrm{TiO}_{2}$ Heterostructures with 109 Domain Walls. Journal of Alloys and Compounds, 628, 311-316. http://dx.doi.org/10.1016/j.jallcom.2014.11.211

[3] Chida, H.U., Veno, R., Funakubu, H. and Koda, S. (2006) Crystal Structure and Ferroelectric Properties of Rare-Earth Substituted $\mathrm{BiFeO}_{3}$ Thin Films. Journal of Applied Physics, 100, Article ID: 014106.

[4] Raghavan, C.M., Kim, J.W. and Kim, S.S. (2014) Effects of Ho and Ti Doping on Structural and Electrical Properties of $\mathrm{BiFeO}_{3}$ Thin Films. Journal of the American Ceramic Society, 97, 235-240. http://dx.doi.org/10.1111/jace.12641

[5] Kothari, D., Raghavendra Reddy, V., Gupta, A., Phase, D.M., Lakshmi, N., Despande, S.K. and Awasthi, A.M. (2007) Study of the Effect of Mn Doping on the $\mathrm{BiFeO}_{3}$ System. Journal of Physics: Condensed Matter, 19, Article ID: 136202. http://dx.doi.org/10.1088/0953-8984/19/13/136202

[6] Prellier, W., Singh, M.P. and Murugavel, P. (2005) The Single-Phase Multiferroic Oxides: from Bulk to Thin Film. Journal of Physics: Condensed Matter, 17, R803. http://dx.doi.org/10.1088/0953-8984/17/30/R01

[7] Kim, T.Y., Hong, N.H., Sugawara, T., Raghavender, A.T. and Kurisu, M. (2013) Room Temperature Ferromagnetism with Large Magnetic Moment at Low Field in Rare-Earth-Doped $\mathrm{BiFeO}_{3}$ Thin Films. Journal of Physics: Condensed Matter, 25, Article ID: 206003. http://dx.doi.org/10.1088/0953-8984/25/20/206003

[8] Raghavender, A.T. and Hong, N.H. (2011) Effects of Mn Doping on Structural and Magnetic Properties of Multiferroic $\mathrm{BiFeO}_{3}$ Nanograins Made by Sol-Gel Method. Journal of Magnetics, 16, 19-22. http://dx.doi.org/10.4283/JMAG.2011.16.1.019

[9] Wang, D.H., Goh, W.C., Ning, M. and Ong, C.K. (2006) Effect of Ba Doping on Magnetic, Ferroelectric, and Magnetoelectric Properties in Mutiferroic $\mathrm{BiFeO}_{3} \mathrm{BiFeO}_{3}$ at Room Temperature. Journal of Applied Physics Letters, 88, 1.

[10] Cheng, Z., Wang, X., Dou, S., Kimura, H. and Ozawa, K. (2008) Improved Ferroelectric Properties in Multiferroic Bi$\mathrm{FeO}_{3}$ Thin Films through La and Nb Co Doping. Physical Review B, 77, Article ID: 092101. http://dx.doi.org/10.1103/PhysRevB.77.092101

[11] Ghosh, A.K., Kevin, H., Chatterjee, B., Dwivedi, G.D., Barman, A., Yang, H.D. and Chatterjee, S. (2012) Effect of SrDoping on Multiferroic Properties of $\mathrm{Bi}_{0.8} \mathrm{La}_{0.2} \mathrm{Fe}_{0.9} \mathrm{Mn}_{0.1} \mathrm{O}_{3}$. Solid State Communications, 152, 557-560. http://dx.doi.org/10.1016/j.ssc.2011.12.027

[12] Makhdoom, A.R., Akhtar, M.J., Rafiq, M.A. and Hassan, M.M. (2012) Investigation of Transport Behavior in Ba Doped $\mathrm{BiFeO}_{3}$. Ceramics International, 38, 3829-3834. http://dx.doi.org/10.1016/j.ceramint.2012.01.032

[13] Qi, X., Dho, J., Tomov, R., Blamire, M.G. and MacManus-Driscoll, J.L. (2005) Greatly Reduced Leakage Current and Conduction Mechanism in Aliovalent-Ion-Doped $\mathrm{BiFeO}_{3}$. Journal of Applied Physics Letters, 86, Article ID: 062903. http://dx.doi.org/10.1063/1.1862336

[14] Raghavender, A.T., Pajic, D., Zadro, K., Milekovic, T., Rao, P.V., Jadhav, K.M. and Ravinder, D. (2007) Synthesis and Magnetic Properties of $\mathrm{NiFe}_{2-} \mathrm{Al}_{x} \mathrm{O}_{4}$ Nanoparticles. Journal of Magnetism and Magnetic Materials, 316, 1-7. http://dx.doi.org/10.1016/j.jmmm.2007.03.204

[15] Raghavender, A.T., Hong, N.H., Park, C., Jung, M.-H., Lee, K.-J. and Lee, D. (2011) Thickness Dependent Magnetic Properties of $\mathrm{BiFeO}_{3}$ Thin Films Prepared by Pulsed Laser Deposition. Materials Letters, 65, 2786-2788. http://dx.doi.org/10.1016/j.matlet.2011.05.060

[16] Rojas-George, G., Concha-Balderrama, A., Silva, J., Fuentes, L. and Reyes-Rojas, A. (2015) Elucidating the Real Effect of $\mathrm{Ba}$ and $\mathrm{Co}$ Doping on the Magnetic and Optical Properties of $\mathrm{BiFeO}_{3}$. Ceramics International, 41, 9140-9145. http://dx.doi.org/10.1016/j.ceramint.2015.03.322

[17] Berbenni, V., Milanese, C., Broni, G., Girella, A. and Marini, A. (2015) Mechanical Activation of the Solid-Phase Reaction between Bismuth Citrate and Iron(II) Oxalate Dihydrate to Yield $\mathrm{BiFeO}_{3}$. Ceramics International, 41, 72167220. http://dx.doi.org/10.1016/j.ceramint.2015.02.057

[18] El-Desoky, M.M., Ayoua, M.S., Mostafa, M.M. and Ahmed, M.A. (2016) Multiferroic Properties of Nano Structured Barium Doped Bismuth Ferrite. Journal of Magnetism and Magnetic Materials, 404, 68-73. http://dx.doi.org/10.1016/j.jmmm.2015.12.020

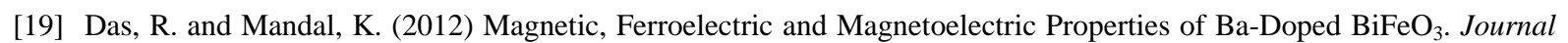
of Magnetism and Magnetic Materials, 324, 1913-1918. http://dx.doi.org/10.1016/j.jmmm.2012.01.022

[20] Mandal, S.K., Rakshit, T., Ray, S.K., Mishra, S.K., Krishna, P.S.R. and Chandra, A. (2013) Nanostructures of Sr2+ Doped $\mathrm{BiFeO}_{3}$ Multifunctional Ceramics with Tunable Photoluminescence and Magnetic Properties. Journal of Physics: Condensed Matter, 25, Article ID: 055303. http://dx.doi.org/10.1088/0953-8984/25/5/055303

[21] Dhir, G., Uniyal, P. and Verma, N.K. (2014) Effect of Particle Size on Multiferroism of Barium-Doped Bismuth Ferrite Nanoparticles. Materials Science in Semiconductor Processing, 27, 611-618. http://dx.doi.org/10.1016/j.mssp.2014.07.041

[22] Qian, F.Z., Jiang, J.S., Guo, S.Z., Jiang, D.M. and Zhang, W.G. (2009) Multiferroic Properties of $\mathrm{Bi}_{1-x} \mathrm{Dy}_{x} \mathrm{FeO}_{3} \mathrm{Nano}$ 
Particles. Journal of Applied Physics, 106, Article ID: 084312. http://dx.doi.org/10.1063/1.3245390

[23] Pardo, V. and Pickett, W.E. (2008) Magnetism from 2p States in Alkaline Earth Monoxides: Trends with Varying N Impurity Concentration. Physical Review B, 78, Article ID: 134427. http://dx.doi.org/10.1103/PhysRevB.78.134427

[24] Bhushan, B., Basumallick, A., Bandhopadhyay, S.K., Vasanth Acharya, N.Y. and Das, D. (2009) Effect of Alkaline Earth Metal Doping on Thermal, Optical, Magnetic and Dielectric Properties of $\mathrm{BiFeO}_{3}$ Nanoparticles. Journal of Physics D: Applied Physics, 42, Article ID: 065004. http://dx.doi.org/10.1088/0022-3727/42/6/065004 